Acta Genet Med Gemellol 42: 171-184 (1993)

(C) by The Mendel Institute, Rome

Received 28 January 1993

Final 18 April 1994

\title{
Breathing Patterns of Monozygous Twins during Behavioural Tasks
}

\author{
S.A. Shea', T. Pham Dinh ${ }^{2}$, R.D. Hamilton ${ }^{3}$, A. Guz ${ }^{3}$ and G. Benchetrit ${ }^{4}$ \\ ${ }^{1}$ Physiology Program, Harvard School of Public Health, Boston, USA; ${ }^{2}$ Laboratoire d'Informa- \\ tique et de Mathematiques Appliques de Grenoble, France; ${ }^{3}$ Department of Medicine, Char- \\ ing Cross and Westminster Medical School, London, UK; and ${ }^{4}$ Laboratoire de Physiologie, \\ Faculte de Medecine de Grenoble, France
}

\begin{abstract}
To better understand behavioural and genetic influences upon breathing, the breathing patterns of 8 pairs of monozygous (MZ) twins were measured under 4 behavioural conditions; relaxed without standardisation; eyes closed; eyes open; and reading. Breathing was quantified by inspiratory and expiratory durations $\left(T_{I}, T_{E}\right)$, tidal volume $\left(\mathrm{V}_{\mathrm{T}}\right)$ and derived variables. Airflow shape was normalised and quantified using 8 dimensions. Reading caused breathing to increase by $>500 \mathrm{ml} / \mathrm{min}$ compared to the other four conditions. Differences in breathing between combinations of two conditions were compared by testing whether the differences within an individual were smaller than the differences between random pairs of individuals from the same 16 subjects. For almost all respiratory variables, and whatever the behavioural condition, there were highly significant similarities within an individual ( $\mathrm{p}<0.00025$ on $32 / 80$ comparisons). Under each condition, the differences within $M Z$ twin-pairs were compared to the differences within random-pairs from the same subject population. There were highly significant similarities within twin-pairs for the airflow shape across all conditions. However, $T_{I}, T_{E}$ and $V_{T}$ failed to consistently show significant similarities within twin pairs. Hence, an individual's airflow shape appears to be a fundamental characteristic which is conserved when behavioural condition and level of ventilation changes. Further, MZ twins have similar airflow shapes - whatever the behavioural situation. Hence, behavioural influences upon airflow shape act upon monozygous twin pairs in similar ways, or such influences were negligible under the conditions of the present study.
\end{abstract}

Key words: Breathing, Statistics, Behaviour, Mental tasks, Ventilation 


\section{INTRODUCTION}

We have demonstrated previously that, in adults at rest, there are large differences between people in the ways in which they breathe: each person possesses a characteristic pattern in terms of individual respiratory variables (ie. inspiratory and expiratory durations and depth of breathing [19] and also of the shape of the inspiratory and expiratory airflow profile [4]). In adults, these respiratory parameters are maintained over a long period of time (4-5 years: Benchetrit et al [5]). It seems possible that the airflow shape and the breathing pattern parameters reflect basic characteristics of the automatic brain stem respiratory controller [23]. Indeed, it has been shown recently that the airflow shape is preserved under hypoxic conditions, which induce a reflex increase in ventilation [8]. In the present study, we wished to test the effect of a behavioural stimulus which probably acts via the forebrain - upon the fundamental pattern of the brain stem respiratory controller.

We have previously found that $\mathrm{MZ}$ twins breathe in similar ways when awake at rest and concluded that there may be a genetic influence upon the characteristic pattern of breathing [22]. Therefore, by performing the present study on MZ twins we were able to test whether twins still have similar breathing patterns when under different behavioural conditions. Our rationale is that the breathing pattern is generated by the brain stem controller but is further shaped by the anatomy of the peripheral respiratory apparatus and the variable forebrain/behavioural inputs. The observations that $\mathrm{MZ}$ twins have similar breathing patterns at rest and similar reflex ventilatory responses to hypoxia and hypercapnia $[12,20]$ suggests that $M Z$ twins share similarities in the automatic brain stem respiratory controller. Furthermore, a very similar anatomy of the respiratory apparatus has been previously observed in monozygous twins [13,17]. Hence, it appears likely that the greatest potential for variability in breathing between MZ twins would stem from differences in forebrain/behavioural influences upon respiratory rhythm generation.

As behavioural stimuli we chose experimental conditions which have been shown to significantly affect the pattern of breathing but affect minimally the overall level of ventilation [20]. We have analysed these data to see whether the different conditions affect the breathing level, the rate and depth, and the shape of the airflow profile within an individual. We also tested whether pairs of $\mathrm{MZ}$ twins could be identified from among other subjects merely by their breathing patterns or airflow shapes when under these different behavioural conditions.

\section{METHODS}

\section{Subjects}

The study was performed on 8 pairs of healthy MZ twins ( 4 female and 4 male pairs) aged between 18 and 27 years. Each pair were reared together; all except one pair were non-smokers. They were volunteers from the twin register of the Institute of Psychiatry in London, naive as to the purpose of the study and were paid for their participation. Homozygocity was ascertained medically at birth and by a questionnaire concerning physical resemblances completed by the adult twins. 


\section{Protocol and Measurements}

The study was approved by the Ethical Committee of Charing Cross Hospital. Each subject attended the laboratory at their own convenience and no attempt was made to control food intake or exercise prior to attendance. The subjects were not informed of the purpose of the study. All individuals were studied within a 2 week period. For all recordings they were seated in a quiet environment, in a room separate from the investigators. A pneumotachometer (Fleisch head No. 1) and a pressure transducer (Validyne; \pm 25 $\mathrm{mmH}_{2} \mathrm{O}$ ) were used for the measurement of respiratory airflow which was recorded on a chart recorder and analogue instrumentation tape. The pneumotachometer was mounted on a comfortable facemask; the total dead space was approximately $50 \mathrm{ml}$. Leaks from around the mask were checked for with an infra-red $\mathrm{CO}_{2}$ analyser (Beckman, LB2).

We recorded breathing under five different conditions:

(i) Rest 1. This was the first recording for the individual, lasting 15-25 minutes. The subjects were asked only to relax, without further standardisation; some subjects chose to close their eyes.

For all other conditions subjects were studied with the same instrumentation. In addition, to ensure that data were used only when subjects were relaxed but still awake, two electroencephalograms (EEG: electrode placements $C_{3} / A_{2}$ and $C_{3} / O_{1}$ ) and two electrooculograms (EOG: electrode placements $F_{7} / A_{1}$ and $F_{8} / A_{1}$ ) were recorded. Relaxed wakefulness was confirmed when EEG alpha rhythm $(8-12 \mathrm{~Hz})$ was present, and there were no signs of light sleep. They were then studied for 5 minutes per condition under the following 3 experimental conditions which were more standardised than Rest 1. The order of these conditions was randomised for each subject.

(ii) Eyes Closed. The subjects' eyes were closed and covered with a blindfold; they wore soundproof headphones and were asked to relax but to remain awake. There was a minimum of activity and tactile input.

(iii) Eyes Open. This was identical to the "eyes-closed" condition except that the subjects were not blindfolded and the eyes were open and directed at a clean white viewing box at $75 \mathrm{~cm}$ which emitted 570 lux at this distance. In order to discourage the subjects from scanning the edges of the viewing box - thereby ensuring an "even " visual stimulation throughout the test - a light blue spot was drawn in the centre of the viewing box which the subjects were asked to focus on.

(iv) Reading. This was identical to the "eyes-open" condition except that the white light was replaced with the reading of a standard text with enough concentration to answer simple questions on its content at the end of the experiment. The page was illuminated by a light source from behind the subject. The text was an article taken from the "Guardian" newspaper describing reductions in the British Government's grant to the Arts Council. It was lengthy, long out of date, and judged to be unemotive by readers in preliminary experiments.

(v) Rest 2. Upon the completion of these standardised conditions, a repeat recording was made under the "unstandardised" Rest 1 condition and this was termed Rest 2.

Subsequently, the subjects underwent a structured interview concerning any smoking habits, respiratory illnesses and their impressions during the recording eg. whether they had been thinking about their breathing; whether they had fallen asleep or felt drowsy; 
what they could recall from the reading material. Their heights and weights were measured and they performed a maximum forced expiratory manoeuvre on a spirometer from which the forced vital capacity (FVC) and the forced expired volume in one second $\left(\mathrm{FEV}_{1,0}\right)$ were calculated.

\section{Airflow Signal Analysis}

The analysis was performed off-line on an Apple IIe microcomputer having an analogue-digital interface card. For each subject all recorded breaths were digitized at a frequency which gave $>100$ points per breath. A breath-by-breath analysis was performed but all breaths where disturbances occurred ie. swallowing, a sigh, or a body movement were discarded; the three breaths immediately following such events were also discarded.

For each breath the airflow shape, normalised for breath duration and amplitude, was analysed using harmonic analysis as described previously $[3,8]$. This analysis provides 8 variables which correspond to the cartesian coordinates of the vectorial representation of the amplitudes and phase angles of the fundamental and first three harmonics, normalised for amplitude. The original airflow profile can be reconstructed from these 8 variables. Together these variables carry $\geq 95 \%$ of the power of the original digitised airflow signal for breathing patterns measured in healthy subjects at rest, during exercise and during hypoxia [3,8]. This multivariate representation of normalised airflow shape has been termed an "ASTER".

In addition, the following variables were derived for each breath: inspiratory duration $\left(\mathrm{T}_{\mathrm{I}}\right)$, expiratory duration $\left(\mathrm{T}_{\mathrm{E}}\right)$, total breath duration $\left(\mathrm{T}_{\mathrm{TOT}}\right)$, tidal volume $\left(\mathrm{V}_{\mathrm{T}}\right)$, $\mathrm{V}_{\mathrm{T}} / \mathrm{T}_{\mathrm{I}}$ and $\mathrm{T}_{\mathrm{I}} / \mathrm{T}_{\mathrm{TOT}}$. To enable the comparison of the pattern of breathing, the primary respiratory variables $\left(T_{I}, T_{E}\right.$ and $\left.V_{T}\right)$ were grouped together as a trivariate description of the "volume shape" for each breath; we have termed this a "TRIAD". The TRIAD complements the ASTER in the complete description of breathing pattern since it contains those dimensions which were stripped from the ASTER in the process of normalisation.

\section{Statistical Analysis}

The mean and standard deviation were calculated for each variable and for the multivariate ASTER and TRIAD within each recording.

(i) Between Conditions. In order to assess the general effect of changing the experimental condition, the mean levels of ventilation were compared between conditions using paired t-tests for the group treated as 16 individuals (ie. ignoring twin pairs).

For the other 8 variables $\left(\mathrm{V}_{\mathrm{T}} ; \mathrm{T}_{\mathrm{TOT}} ; \mathrm{T}_{\mathrm{I}} ; \mathrm{T}_{\mathrm{E}} ; \mathrm{V}_{\mathrm{T}} / \mathrm{T}_{\mathrm{I}} ; \mathrm{T}_{\mathrm{I}} / \mathrm{T}_{\mathrm{TOT}} ;\right.$ ASTER; TRIAD), in order to test whether the pattern of breathing was similar within an individual between any two conditions, those differences within an individual were compared with those differences observed between random pairs of individuals from the same population. Such an analysis allows for differences within an individual between conditions, 
but implies that an individual has a certain "trait" which can be recognised amongst other individuals whatever the experimental condition.

In order to compare between the 5 conditions, all 10 combinations of two conditions were analysed separately. Also, each variable was treated separately. The differences within and between individuals were expressed in terms of a statistical "distance" [15]. For a single variable (ie. $T_{I}, T_{E}, T_{T O T}, V_{T}, V_{T} / T_{I}$ and $T_{I} / T_{T O T}$ ) this "distance" is calculated as the square of the difference between the means, divided by the pooled variance; for the equivalent multivariate determination of "distance" (necessary for ASTERs and TRIADs) the covariances between the different variables are also taken into account.

The statistical analysis was done by comparing the differences between two conditions within the 16 individuals with those differences observed between random pairs of recordings from the same 16 individuals under these two conditions ( 32 recordings). The Mahalanobis distance was calculated from each recording in one condition to each of the other 31 recordings in the other relevant condition. These distances were ranked as integers from 1 to 31,1 being the smallest distance. This provided 32 sets of 31 ranked distances; the ranks of distances within the 16 individuals were summed and this became the test statistic $T$. To test whether statistic $T$ is less than the sum of the ranks from 16 pairs of recordings taken randomly $\left(T^{\prime}\right)$ it would have been necessary to compute the probability distribution of $T^{\prime}$ from all possible permutations of 16 pairs from these 32 recordings. There are $32 ! /\left(2^{16} \times 16\right.$ !) possible permutations and it was impractical to compute the sum T' for all of these. Therefore, the "Monte-Carlo" technique was adopted [24] to estimate the frequency distribution of T' by taking 4000 samples of 16 random pairs. By chance (approximately once every 31 samples), some of these random pairs will correspond to the two recordings within the same individual; leading to a more powerful statistical test. The probability of the test statistic $T$ occurring by chance can then be estimated by the area under the frequency distribution of 'T' to the left of $T$; because there are 4000 sample determinations of ' $T$ ', the minimum probability which we could derive is $1 / 4000$. This is a one-tailed probability test; the null hypothesis $\left(\mathrm{H}_{\mathrm{o}}\right)$ is that the sum of the ranks between conditions within an individual (T) is not different from the sum of the ranks from pairs of individuals taken randomly ( $\left.T^{\prime}\right)$; the alternative hypothesis $\left(\mathrm{H}_{1}\right)$ is that $\mathrm{T}$ is less than T'.

(ii) Within twin pairs. Here, each condition was treated separately. In order to test whether the pattern of breathing was similar within pairs of related twins, those differences within the related twin pairs were compared with those differences observed within random pairs of two individuals from the same population. This was an analogous comparison to that described above for comparisons between two recordings within the same individual. Hence, the analysis allows for differences within a twin pair, but implies that the twin pairs have a certain "trait" which can be recognised amongst other individuals. The statistical analysis was done by comparing differences between the 1 st twin and the 2nd twin for each pair of twins with those differences observed between random pairs of recordings from the same 8 pairs of twins ( 16 recordings). The differences between individuals were expressed in terms of Mahalanobis distance (see above). Within each condition, the Mahalanobis distance was calculated from each recording to each of the other 15 recordings and ranked. This provided 16 sets of 15 ranked distances; the ranks of distances within the 8 twin pairs were summed and this became the test statistic $T$. 
To test whether $\mathrm{T}$ is less than the sum of the ranks from 8 pairs of recordings taken randomly (T') it was impractical to compute the probability distribution of ' $\mathrm{T}$ ' from all $\left(16 ! /\left[2^{8} \times 8 !\right]\right)$ possible permutations of 8 pairs from these 16 recordings. Therefore, the "Monte-Carlo" technique was used to estimate the frequency distribution of $T$ ' by taking 4000 samples of 8 random pairs. The null hypothesis $\left(H_{o}\right)$ is that the sum of the ranks within-twin pairs $(T)$ is not different from the sum of the ranks from pairs taken randomly ( $\left.T^{\prime}\right)$; the alternative hypothesis $\left(H_{1}\right)$ is that $T$ is less than $T$ '.

\section{RESULTS}

\section{Characteristics of the subjects}

The subjects' physical characteristics and indices of lung function are presented in Table 1. It can be seen that height and the parameters of lung function were very similar within each pair of $\mathrm{MZ}$ twins. There were large differences in weight within some of the pairs (eg. pairs 6 and 7). None of the subjects reported having any history of respiratory illness. All except two of the subjects (1st twin of pair 6 and 2 nd twin of pair 7 ) had normal

Table 1 - Subjects' characteristics and ventilation during different experimental conditions

\begin{tabular}{|c|c|c|c|c|c|c|c|c|c|c|}
\hline Twin Pair & $\begin{array}{l}\text { Gender } \\
\text { and age }\end{array}$ & $\begin{array}{l}\text { Height } \\
\text { (cm) }\end{array}$ & $\begin{array}{c}\text { Weight } \\
\text { (kg) }\end{array}$ & $\begin{array}{l}\text { FVC } \\
\text { (I) }\end{array}$ & $\begin{array}{l}\mathrm{FEV}_{1.0} \\
\text { (I) }\end{array}$ & $\begin{array}{l}\dot{\mathrm{V}}_{\mathrm{I}} \\
\operatorname{REST} 1 \\
(\mathrm{I} / \mathrm{min})\end{array}$ & $\begin{array}{c}\dot{\mathrm{V}}_{\mathrm{I}} \\
\mathrm{EC} \\
(\mathrm{I} / \mathrm{min})\end{array}$ & $\begin{array}{c}\dot{\mathrm{V}}_{\mathrm{I}} \\
\mathrm{EO} \\
(\mathrm{I} / \mathrm{min})\end{array}$ & $\begin{array}{c}\dot{\mathbf{V}}_{\mathbf{I}} \\
\mathbf{R} \\
(\mathbf{I} / \mathrm{min})\end{array}$ & $\begin{array}{c}\dot{\mathrm{V}}_{\mathrm{I}} \\
\mathrm{REST} 2 \\
(\mathrm{I} / \mathrm{min})\end{array}$ \\
\hline 1 1st twin & female & 161 & 64 & 4.2 & 3.4 & 7.2 & 7.0 & 7.7 & 8.0 & 7.5 \\
\hline 2nd twin & $18 \mathrm{yr}$ & 162 & 63 & 4.1 & 3.8 & 6.3 & 7.6 & 7.5 & 8.5 & 7.3 \\
\hline 2 1st twin & male & 165 & 62 & 5.3 & 4.4 & 8.2 & 7.2 & 8.5 & 8.5 & 8.9 \\
\hline 2nd twin & $21 \mathrm{yr}$ & 163 & 56 & 5.2 & 4.5 & 7.2 & 9.3 & 8.6 & 8.6 & 8.1 \\
\hline 31 st twin & female & 170 & 69 & 4.4 & 3.7 & 7.4 & 7.7 & 7.6 & 7.9 & 7.5 \\
\hline 2nd twin & $26 \mathrm{yr}$ & 171 & 68 & 4.0 & 3.5 & 6.9 & 5.7 & 6.5 & 6.9 & 5.0 \\
\hline 4 1st twin & male & 166 & 60 & 4.7 & 3.7 & 7.6 & 6.6 & 7.2 & 8.6 & 6.8 \\
\hline 2nd twin & $22 \mathrm{yr}$ & 166 & 56 & 4.4 & 3.3 & 6.4 & 5.5 & 7.1 & 6.8 & 5.2 \\
\hline 5 1st twin & female & 170 & 56 & 3.5 & 3.2 & 6.2 & 6.8 & 6.5 & 6.5 & 6.5 \\
\hline 2nd twin & $24 \mathrm{yr}$ & 167 & 59 & 3.2 & 3.0 & 5.6 & 5.4 & 5.5 & 6.4 & 5.4 \\
\hline 61 st twin & male & 184 & 82 & 6.5 & 5.8 & 6.6 & 6.0 & 6.4 & 6.6 & 6.3 \\
\hline 2nd twin & $27 \mathrm{yr}$ & 184 & 74 & 6.5 & 5.2 & 7.0 & 5.9 & 6.1 & 6.9 & 7.3 \\
\hline 7 1st twin & female & 176 & 79 & 4.7 & 4.1 & 7.6 & 7.6 & 7.4 & 7.8 & 8.5 \\
\hline 2nd twin & 19 yr & 177 & 73 & 4.8 & 4.4 & 6.9 & 6.9 & 6.9 & 7.2 & 6.8 \\
\hline \multirow{4}{*}{$\begin{array}{l}8 \text { 1st twin } \\
\text { 2nd twin }\end{array}$} & male & 185 & 71 & 5.9 & 5.5 & 10.5 & 8.2 & 8.2 & 9.4 & 9.2 \\
\hline & $22 \mathrm{yr}$ & 185 & 73 & 6.0 & 5.5 & 5.0 & 6.4 & 5.2 & 6.5 & 4.4 \\
\hline & & & & GROUP & mean & 7.0 & 6.9 & 7.1 & 7.6 & 6.9 \\
\hline & & & & & sd & 1.2 & 1.1 & 1.0 & 1.0 & 1.4 \\
\hline
\end{tabular}

$\dot{\mathrm{V}}_{\mathrm{l}}=$ ventilation; $\mathrm{EC}=$ eyes closed; $\mathrm{EO}=$ eyes open: $\mathrm{R}=$ reading. 
lung function, ie. within the predicted range derived from healthy individuals of the same sex, height and age [7]. These other two subjects were unrelated, were both nonsmokers and had values of $\mathrm{FEV}_{1.0}$ which were slightly above predicted. All subjects reported that they were able to relax without falling asleep throughout the studies; lack of sleep was confirmed from analysis of the EEG and EOG recordings.

\section{Between conditions (ignoring twin pairs)}

Level of Ventilation. Table 1 also contains the mean level of ventilation for each subject and the group's mean ventilation in each of the 5 experimental conditions. It can be seen that ventilation is, on average, least when under the baseline standardised condition with eyes closed, and most whilst reading. The differences between the reading condition and all of the other conditions were significant $(\mathrm{p}<0.02$; paired $\mathrm{t}$-tests between conditions - ignoring twin pairs). For all other comparisons between conditions $p>0.2$. Hence, reading leads systematically to a small but significant increase in breathing level.

The mean values of the primary respiratory variables, $V_{T}, T_{I}$ and $T_{E}$, are shown in Fig. 1 for the 16 individuals (separated into twin pairs) under the 5 experimental conditions. From these TRIAD representations it can be seen that there are some differences within an individual between conditions, but these are usually smaller than the differences between random pairs. The exceptions are the 1st twin of pair 4 during REST 2; the 2 nd twin of pair 6 during REST 1; the 1 st twin of pair 7 during R; and the 2 nd twin of pair 8 during $R$ and REST 2 .

The normalised average airflow shapes, reconstructed from the 8 variables derived in the harmonic analysis, are shown in Fig. 2 for all individuals under each condition, separated into twin pairs. Looking at the individuals, Fig. 2 shows that there are striking similarities in the airflow profile within an individual under all conditions (apart from the 1 st twin of pair 7 during REST 2 , and the 2 nd twin of pair 8 during EO). It can also be seen that there are marked differences in the airflow profile between unrelated individuals under all conditions.

The results of the "Monte-Carlo" statistical analyses between conditions, are shown in Table 2 for all respiratory variables. For almost all variables, and whatever the behavioural condition, there were highly significant similarities within an individual relative to those differences occurring between random-pairs. Indeed, the sum of the ranks of distances within the 16 individuals was less than the sum of the ranks from any of the 4000 samples of 16 random individuals (ie. $p<0.00025$ ) on 32 out of the 80 tests. This within-subject similarity between conditions was best demonstrated by the multivariate ASTER and the TRIAD.

\section{Within Twin Pairs}

From the TRIAD representations in Fig. 1 it can be seen that there are some differences within twin-pairs under each condition, but these are usually smaller than the differences between random pairs. The exception is twin pair 8 who had greatly different patterns during all conditions apart from when reading. 

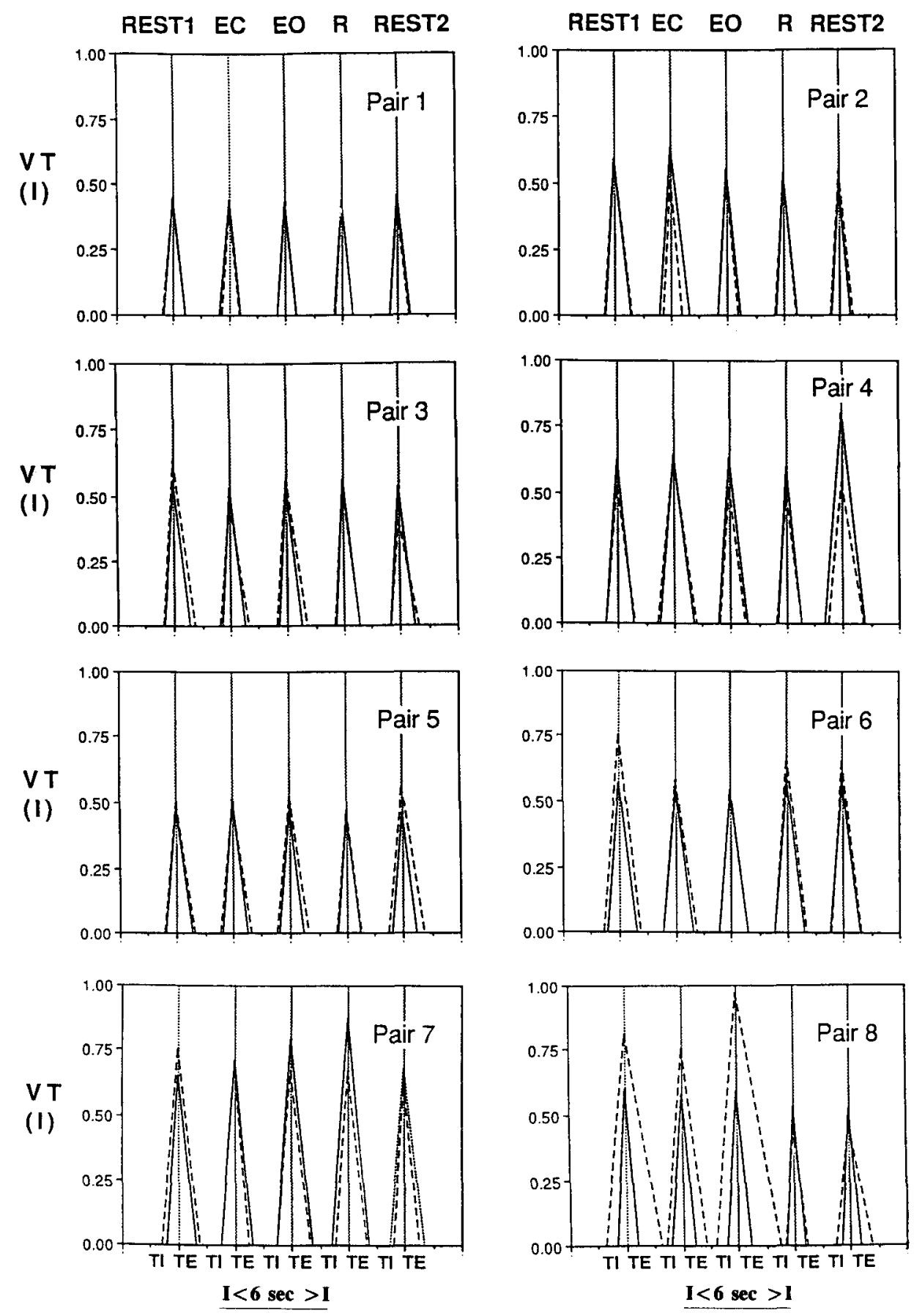

Fig. 1 - The average inspiratory duration $\left(T_{1}\right)$, expiratory duration $\left(T_{E}\right)$ and tidal volume $\left(V_{T}\right)$ of all subjects, separated into behavioural state and twin pairs (for each pair lst twin is represented by a solid line and 2 nd twin by a dotted line - see Table 1). These "TRIADs" represent approximately 50 breaths recorded per subject per condition. 
REST 1

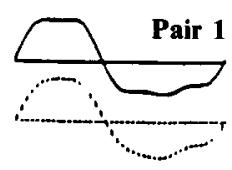

EC

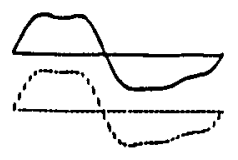

EO

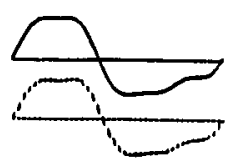

$\mathbf{R}$

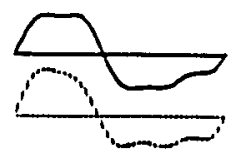

REST 2

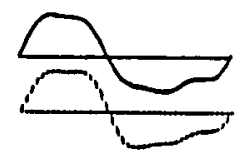

REST 1

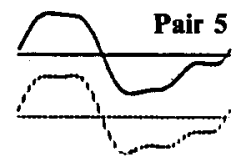

EC

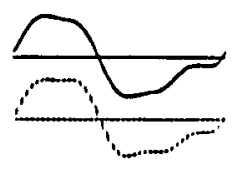

EO

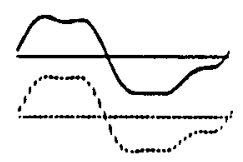

$\mathbf{R}$

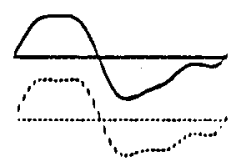

REST 2

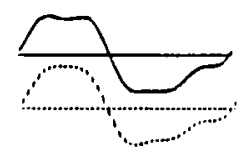

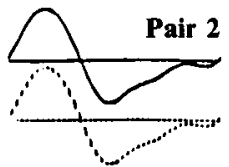
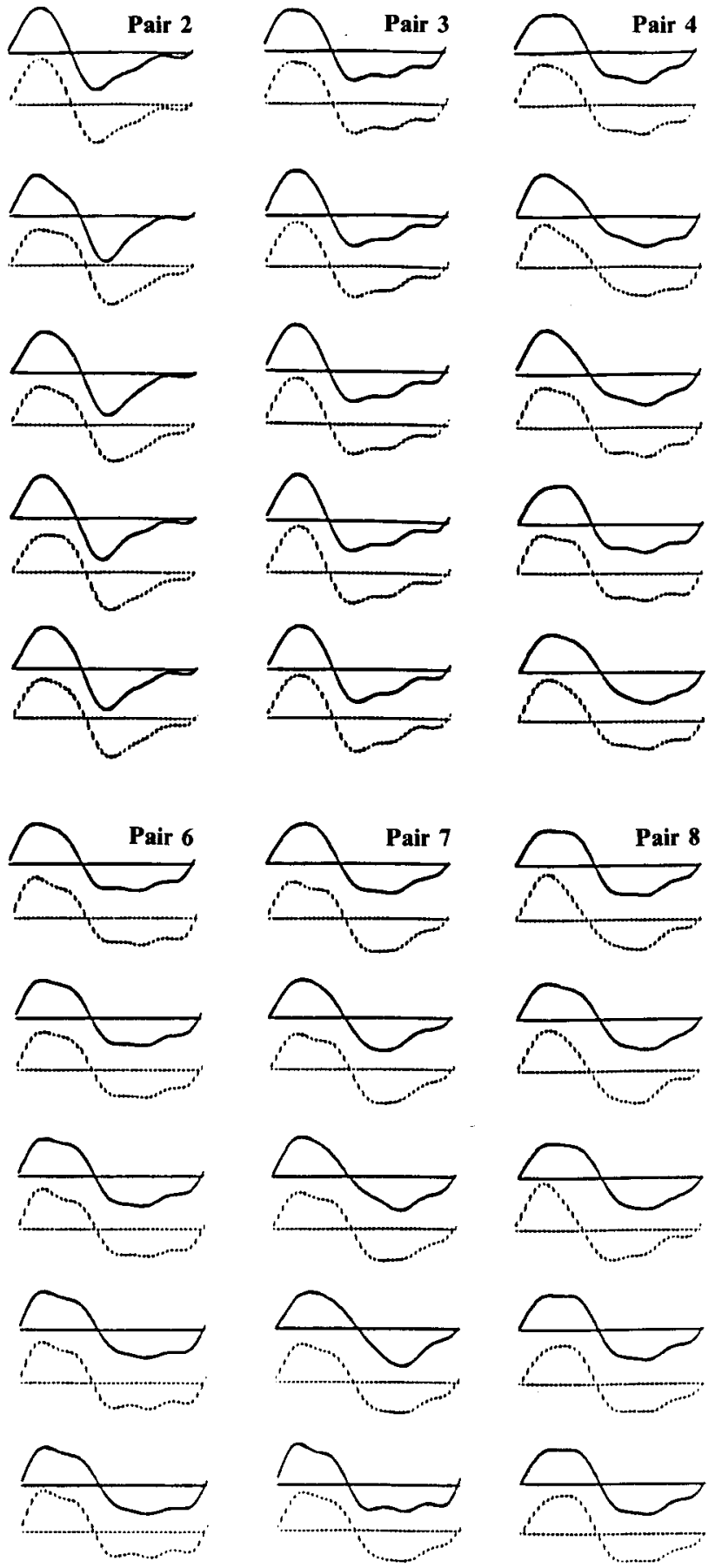

Fig. 2 - The average airflows of all subjects, separated into twin pairs and behavioural state. The shapes were reconstrusted from the $\mathbf{8}$ variables derived during harmonic analysis of the digitised airflow signal (approximately 50 breaths recorded per subject per condition), and are normalised for breath duration and amplitude. 
Table 2 - Values in table are the test statistic $\mathbf{T}_{\text {[observed] }}$ between pairs of conditions (ie. sum of the ranks of Mahalanobis distance within 16 individuals relative to random pairings from the same 32 recordings). $P$ is derived from the estimated probability distribution (see Methods). If $\mathbf{T}_{\text {[observed] }}$ is small, this indicates that the differences within an individual between conditions are small relative to differences occurring between random pairs of individuals from the same 32 recordings.

\begin{tabular}{|c|c|c|c|c|c|c|c|c|}
\hline & ASTER & TRIAD & VT & TTOT & TI & TE & $\mathrm{VT} / \mathrm{TI}$ & TI/TTOT \\
\hline REST 1/EC & $\begin{array}{c}84 \\
p<0.00025\end{array}$ & $\begin{array}{c}218 \\
p<0.00025\end{array}$ & $\begin{array}{c}271 \\
p<0.00025\end{array}$ & $\begin{array}{c}315 \\
p=0.00525\end{array}$ & $\begin{array}{c}347 \\
p=0.169\end{array}$ & $\begin{array}{c}284 \\
p<0.00025\end{array}$ & $\begin{array}{c}434 \\
p=0.21012\end{array}$ & $\begin{array}{c}387 \\
p=0.0275\end{array}$ \\
\hline REST 1/EO & $\begin{array}{c}56 \\
p<0.00025\end{array}$ & $\begin{array}{c}139 \\
p<0.00025\end{array}$ & $\begin{array}{c}218 \\
p<0.00025\end{array}$ & $\begin{array}{c}293 \\
p=0.00050\end{array}$ & $\begin{array}{c}289 \\
p=0.00050\end{array}$ & $\begin{array}{c}304 \\
\mathrm{p}<0.00025\end{array}$ & $\begin{array}{c}313 \\
p=0.00275\end{array}$ & $\begin{array}{c}290 \\
p=0.0005\end{array}$ \\
\hline REST $1 / R$ & $\begin{array}{c}113 \\
p<0.00025\end{array}$ & $\begin{array}{c}219 \\
p<0.00025\end{array}$ & $\begin{array}{c}296 \\
p=0.00050\end{array}$ & $\begin{array}{c}397 \\
p=0.03175\end{array}$ & $\begin{array}{c}393 \\
p=0.02675\end{array}$ & $\begin{array}{c}373 \\
p=0.01150\end{array}$ & $\begin{array}{c}318 \\
p=0.00200\end{array}$ & $\begin{array}{c}391 \\
p=0.0272\end{array}$ \\
\hline REST 1/REST 2 & $\begin{array}{c}76 \\
p<0.00025\end{array}$ & $\begin{array}{c}210 \\
\mathrm{p}<0.00025\end{array}$ & $\begin{array}{c}332 \\
\mathrm{p}=0.00225\end{array}$ & $\begin{array}{c}350 \\
\mathrm{p}=0.00750\end{array}$ & $\begin{array}{c}343 \\
p=0.00425\end{array}$ & $\begin{array}{c}337 \\
p=0.00425\end{array}$ & $\begin{array}{c}210 \\
p<0.00025\end{array}$ & $\begin{array}{c}347 \\
p=0.0062\end{array}$ \\
\hline $\mathrm{EC} / \mathrm{EO}$ & $\begin{array}{c}69 \\
p<0.00025\end{array}$ & $\begin{array}{c}139 \\
p<0.00025\end{array}$ & $\begin{array}{c}197 \\
p<0.00025\end{array}$ & $\begin{array}{c}249 \\
\mathrm{p}<0.00025\end{array}$ & $\begin{array}{c}230 \\
p<0.00025\end{array}$ & $\begin{array}{c}262 \\
p<0.00025\end{array}$ & $\begin{array}{c}325 \\
p=0.00275\end{array}$ & $\begin{array}{c}294 \\
p=0.0010\end{array}$ \\
\hline $\mathrm{EC} / \mathrm{R}$ & $\begin{array}{c}105 \\
p<0.00025\end{array}$ & $\begin{array}{c}258 \\
\mathrm{p}<0.00025\end{array}$ & $\begin{array}{c}353 \\
p=0.00600\end{array}$ & $\begin{array}{c}356 \\
p=0.01125\end{array}$ & $\begin{array}{c}384 \\
p=0.02675\end{array}$ & $\begin{array}{c}355 \\
p=0.01125\end{array}$ & $\begin{array}{c}440 \\
p=0.11975\end{array}$ & $\begin{array}{c}356 \\
p=0.00575\end{array}$ \\
\hline EC/REST 2 & $\begin{array}{c}81 \\
p<0.00025\end{array}$ & $\begin{array}{c}184 \\
p<0.00025\end{array}$ & $\begin{array}{c}351 \\
p=0.00650\end{array}$ & $\begin{array}{c}241 \\
\mathrm{p}<0.00025\end{array}$ & $\begin{array}{c}265 \\
p=0.00037\end{array}$ & $\begin{array}{c}247 \\
p<0.00025\end{array}$ & $\begin{array}{c}347 \\
p=0.00575\end{array}$ & $\begin{array}{c}364 \\
p=0.0132\end{array}$ \\
\hline $\mathrm{E} 0 / \mathrm{R}$ & $\begin{array}{c}117 \\
p<0.00025\end{array}$ & $\begin{array}{c}180 \\
p<0.00025\end{array}$ & $\begin{array}{c}303 \\
p=0.00075\end{array}$ & $\begin{array}{c}273 \\
p=0.00025\end{array}$ & $\begin{array}{c}296 \\
p=0.00050\end{array}$ & $\begin{array}{c}249 \\
\mathrm{p}<0.00025\end{array}$ & $\begin{array}{c}332 \\
p=0.00412\end{array}$ & $\begin{array}{c}368 \\
p=0.0117\end{array}$ \\
\hline E0/REST 2 & $\begin{array}{c}125 \\
\mathrm{p}<0.00025\end{array}$ & $\begin{array}{c}201 \\
\mathrm{p}<0.00025\end{array}$ & $\begin{array}{c}333 \\
\mathrm{p}=0.00125\end{array}$ & $\begin{array}{c}290 \\
\mathrm{p}=0.00075\end{array}$ & $\begin{array}{c}312 \\
p=0.00037\end{array}$ & $\begin{array}{c}266 \\
\mathrm{p}<0.00025\end{array}$ & $\begin{array}{c}345 \\
p=0.00475\end{array}$ & $\begin{array}{c}332 \\
p=0.0030\end{array}$ \\
\hline R/REST2 & $\begin{array}{c}142 \\
\mathrm{p}<0.00025\end{array}$ & $\begin{array}{c}224 \\
p<0.00025\end{array}$ & $\begin{array}{c}274 \\
p=0.00037\end{array}$ & $\begin{array}{c}293 \\
p=0.00100\end{array}$ & $\begin{array}{c}317 \\
p=0.00250\end{array}$ & $\begin{array}{c}330 \\
p=0.00375\end{array}$ & $\begin{array}{c}383 \\
p=0.02250\end{array}$ & $\begin{array}{c}354 \\
p=0.0067\end{array}$ \\
\hline
\end{tabular}

$\mathrm{EC}=$ eyes closed; $\mathrm{EO}=$ eyes open; $\mathrm{R}=$ reading; $\mathrm{VT}=$ tidal volume; $\mathrm{TI}=$ inspiratory duration; $\mathrm{TE}=$ expiratory duration, TTOT $=$ breath duration; ASTER, 8-dimensional representation of normalisd airflow shape; TRIAD, TI, TE and VT grouped together.

From the normalised average airflow shapes in Fig. 2 it is evident that there were similarities in the paterns of breathing within the twin pairs and differences between the twin pairs under all conditions (apart from twin pair 8).

The results of the "Monte-Carlo" statistical analyses are shown in Table 3 for all respiratory variables. For the ASTERs, the sum of the ranks between twin pairs $\left(\mathrm{T}_{\text {[ob- }}\right.$ served]) was smaller than for any of the other variables in all conditions. Similarly, the TRIADs give strong evidence for the similarity in the pattern of breathing within twin pairs under all conditions except REST 2. The similarity between the twins can also be demonstrated (at the $5 \%$ level of significance) for $\mathrm{V}_{\mathrm{T}}$ during $\mathrm{EC}, \mathrm{EO}$ and $\mathrm{R}$ but not for either of the "unstandardised" REST conditions. Occasionally, the respiratory timing variables ( $T_{I}, T_{E}$ and $\left.T_{T O T}\right)$ reached significance, but we failed to find any significant similarity within twin pairs for either of the derived respiratory variables $\left(V_{T} / T_{I}\right.$ and 
$\mathrm{T}_{\mathrm{I}} / \mathrm{T}_{\mathrm{TOT}}$ ) during any condition. The condition of reading appeared to produce the best demonstration of similarity in breathing pattern (including respiratory timing) within twin pairs. However, these results were influenced principally by one pair (\#8) alone who had very different breathing patterns except when reading (Figs. 1 and 2). In common with the within subject comparisons between conditions (Table 2), from Table 3 it is evident that the similarity within twin pairs is best demonstrated by taking into account the shape of the whole breath (ASTERs and TRIADs) rather than the individual respiratory variables.

Table 3 - Values in table are the test statistic $\mathbf{T}_{\text {[observed] }}$ (ie. sum of the ranks of Mahalanobis distance within 8 monozygous twin pairs realtive to unrelated pairs from the same 16 recordings). $P$ is derived from the estimated probability distribution (see Methods). If $\mathbf{T}_{\text {[observed] }}$ is small, this indicates that the differences within twin-pairs are small relative to differences occurring between random pairs of individuals from the same 16 individuals.

\begin{tabular}{|c|c|c|c|c|c|c|c|c|}
\hline & ASTER & TRIAD & VT & TTOT & TI & TE & $\mathrm{VT} / \mathrm{TI}$ & TI/TTOT \\
\hline REST 1 & $\begin{array}{c}57 \\
\mathrm{p}=0.00075\end{array}$ & $\begin{array}{c}89 \\
\mathrm{p}=0.02725\end{array}$ & $\begin{array}{c}94 \\
p=0.06375\end{array}$ & $\begin{array}{c}119 \\
\mathrm{p}=0.29700\end{array}$ & $\begin{array}{c}109 \\
p=0.16900\end{array}$ & $\begin{array}{c}117 \\
p=0.26375\end{array}$ & $\begin{array}{c}109 \\
\mathrm{p}=0.20475\end{array}$ & $\begin{array}{c}93 \\
p=0.05575\end{array}$ \\
\hline EC & $\begin{array}{c}57 \\
p=0.00075\end{array}$ & $\begin{array}{c}90 \\
p=0.03333\end{array}$ & $\begin{array}{c}78 \\
p=0.01200\end{array}$ & $\begin{array}{c}117 \\
P=0.28100\end{array}$ & $\begin{array}{c}108 \\
p=0.18200\end{array}$ & $\begin{array}{c}120 \\
\mathrm{p}=0.32525\end{array}$ & $\begin{array}{c}134 \\
p=0.61930\end{array}$ & $\begin{array}{c}103 \\
p=0.12225\end{array}$ \\
\hline EO & $\begin{array}{c}62 \\
p=0.00175\end{array}$ & $\begin{array}{c}69 \\
p=0.00125\end{array}$ & $\begin{array}{c}89 \\
p=0.02350\end{array}$ & $\begin{array}{c}95 \\
\mathrm{p}=0.05875\end{array}$ & $\begin{array}{c}80 \\
p=0.01475\end{array}$ & $\begin{array}{c}101 \\
p=0.10075\end{array}$ & $\begin{array}{c}94 \\
p=0.07300\end{array}$ & $\begin{array}{c}105 \\
p=0.13575\end{array}$ \\
\hline $\mathbf{R}$ & $\begin{array}{c}41 \\
p<0.00025\end{array}$ & $\begin{array}{c}82 \\
p=0.01850\end{array}$ & $\begin{array}{c}78 \\
p=0.01425\end{array}$ & $\begin{array}{c}60 \\
\mathrm{p}=0.00075\end{array}$ & $\begin{array}{c}79 \\
p=0.01175\end{array}$ & $\begin{array}{c}54 \\
p=0.00025\end{array}$ & $\begin{array}{c}140 \\
p=0.69700\end{array}$ & $\begin{array}{c}111 \\
p=0.20175\end{array}$ \\
\hline REST 2 & $\begin{array}{c}58 \\
p=0.00090\end{array}$ & $\begin{array}{c}105 \\
p=0.15725\end{array}$ & $\begin{array}{c}117 \\
p=0.29525\end{array}$ & $\begin{array}{c}90 \\
\mathrm{p}=0.05575\end{array}$ & $\begin{array}{c}95 \\
p=0.07575\end{array}$ & $\begin{array}{c}100 \\
p=0.12000\end{array}$ & $\begin{array}{c}129 \\
\mathrm{p}=0.51950\end{array}$ & $\begin{array}{c}113 \\
p=0.23200\end{array}$ \\
\hline
\end{tabular}

$\mathrm{EC}=$ eyes closed; $\mathrm{EO}=$ eyes open; $\mathrm{R}=$ reading; $\mathrm{VT}=$ tidal volume; $\mathrm{TI}=$ inspiratory duration; $\mathrm{TE}=$ expiratory duration, TTOT $=$ breath duration; ASTER, 8-dimensional representation of normalisd airflow shape; TRIAD, TI, TE and VT grouped together.

\section{DISCUSSION}

\section{Comparisons between conditions}

We found that for almost all respiratory variables, and whatever the behavioural condition, there were highly significant similarities within an individual relative to those differences occurring between random-pairs of individuals. We chose experimental conditions which have been shown to increase the overall level of ventilation (between $6 \%$ and $18 \%$ ), by causing a more rapid and shallow breathing pattern $[2,20,21]$. In the present study, we also found a significant increase in ventilation, but only during the reading condition. Previously, we had no information on airflow shape during these different behaviours. It was interesting to observe that these behaviours did not alter the flow pattern - even when ventilation was significantly increased. 
Subconscious behavioural influences upon breathing may originate within the forebrain and cause changes in respiratory muscle contractions via corticospinal pathways or indirectly via links with the brain stem respiratory controller. That is, forebrain influences can impinge upon or override the brain stem respiratory controller. The present study suggests that an individual's airflow shape is a fundamental characteristic which is not changed significantly by behavioural inputs to the respiratory controller. This finding is similar to that of Eisele et al [8]) who found that hypoxia did not affect the airflow shape either during exercise or during rest (but that exercise itself did affect the pattern). Hypoxia probably reflects a more automatic reflex change in breathing when compared to behavioural changes and it would be fruitful to study this interaction in the same subjects.

\section{Comparisons within monozygous twins}

The second main finding of our study was that there were highly significant similarities within $\mathrm{MZ}$ twin-pairs for the patterns of breathing and the airflow shapes under all behavioural situations. We interpret this as meaning that the behavioural influences upon breathing pattern and airflow shape act in similar ways in the related monozygous twin pairs and/or such influences are negligible under the conditions of the present study.

Our rationale behind studying the $\mathrm{MZ}$ twins is that they can give an insight into the main neurophysiological or anatomical factors which determine the pattern of breathing. The possible determinants include the forebrain/behavioural influences; the neural interconnections within the brain stem respiratory complex itself, the neural connections and bulk of the respiratory pump muscles; and the mechanical characteristics of the airways and lungs and chest wall [23].

There is good evidence that genetic factors influences pulmonary function including the dimensions and function of central airways, peripheral airways, and lung parenchyma in adolescents $[12,14]$. Redline et al[17] demonstrated that even in adults the similarities in various indices of pulmonary function were influenced by genetic factors other than those associated with similarities in body size. In addition, there have been numerous previous studies concerned with the influence of genetic factors upon the ventilatory responses to inhaled $\mathrm{CO}_{2}$ or to hypoxia. These were performed by studying either family relations of athletes or patients with chronic obstructive airways disease $[9,16,18]$, or healthy $\mathrm{MZ}$ and/or DZ twins of different ages [1,6,10-12]. Most of these studies demonstrate that there are significant genetic influences upon the pattern of the ventilatory responses to increased $\mathrm{CO}_{2}$ and hypoxia.

Given the presumed similarities within the twin-pairs in the chemical drives to breathe, in conjunction with similar anatomical and functional properties of the respiratory apparatus (see above, and Tab. 1), in the present study if we had found dissimilarities within twin-pairs then this would probably have reflected differences in brain stem respiratory rhythm generation, or differences in forebrain influences upon breathing. However, since we found similarities in breathing patterns within twin-pairs, then this could signify similarities in brain stem respiratory rhythm generation, and/or in any forebrain influences upon breathing.

The present study was not designed to enable a separation of environmental and 
genetic influences upon the pattern of breathing: differences between $\mathrm{MZ}$ twins are caused entirely by environment/nurture, but the similarities between $\mathrm{MZ}$ twins (which we observed) may be genetic or environmental/nurtural in origin.

Acknowledgements. We wish to thank the Institute of Psychiatry in London for the use of their Twin Register, the twins for the their participation, Robert Lansing for helpful comments on the manuscript and the Wellcome Trust who have generously sponsored this research.

\section{REFERENCES}

1. Arkinstall WW, Nirmel K, Klissouras V, Milic-Emili J (1974): Genetic differences in the ventilatory response to inhaled $\mathrm{CO}_{2}$. J Appl Physiol 36:6-11.

2. Asmussen E (1977): Regulation of respiration: "The Black Box". Acta Physiol Scand 99:85-90.

3. Bachy JP, Eberhard A, Baconnier P, Benchetrit G (1986): A program for cycle-by-cycle analysis of biological rhythms. Application to respiratory rhythm. Comp Meth Prog Biomed 23:297-307.

4. Benchetrit G, Baconnier P, Demongeot J, Pham Dinh T (1987): Flow profile analysis of human breathing at rest. In Benchetrit G (ed): Concepts and Formalizations in the Control of Breathing. Manchester, Manchester University Press, pp. 207-216.

5. Benchetrit G, Shea SA, Pham Dinh T, Bodocco S, Baconnier P, Guz A (1989): Individuality of breathing patterns in adults assessed over time. Respir Physiol 75:199-210.

6. Collins DD, Scoggin CH, Zwillich CW, Weil JV (1978): Hereditary aspects of decreased hypoxic response. J Clin Invest 62: 105-110.

7. Cotes JE (1979): Lung Function. Assessment and Application in Medicine (4th Ed) Oxford: Blackwell Scientific Publications.

8. Eisele JH, Wuyam B, Savourey G, Eterradossi J, Bittel JH, Benchetrit G (1992): Individuality, of breathing patterns during hypoxia and exercise. J Appl Physiol 72:2446-2453.

9. Kawakami Y, Irie T, Shida A, Yoshikawa T (1982a): Familial factors affecting arterial blood gas values and respiratory chemosensitivity in chronic obstructive pulmonary disease. Am Rev Respir Dis 125:420-425.

10. Kawakami Y, Yoshikawa T, Shida A, Asanuma Y, Murao M (1982b): Control of breathing in young twins. J Appl Physiol 52:537-542.

11. Kawakami Y, Yamamoto H, Yoshikawa T, Shida A (1984): Chemical and behavioural control of breathing in adult twins. Am Rev Respir Dis 129:703-707.

12. Kawakami Y, Yamamoto H, Yoshikawa T, Shida A (1985a): Age-related variation in respiratory chemonsensitivity in monozygotic twins. Am Rev Respir Dis 132:89-92.

13. Kawakami Y, Shida A, Yamamoto H, Yoshikawa T (1985b): Pattern of genetic influence on pulmonary function. Chest 87:507-511.

14. Kawakami Y, Kusaka H, Nishimura M, Abe S (1986): Trachea and lung dimensions in nonsmoking twins: morphological and functional studies. J Appl Physiol 61:495-499.

15. Mahalanobis PC (1936): On the generalised distance in statistics. Proc Nat Inst Sci India 12:49-55.

16. Mountain R, Zwillich C, Weil J (1978): Hypoventilation in obstructive lung disease. The role of familial factors. New Engl J Med 298:521-525.

17. Redline S, Tishler PV, Lewitter FI, Tager IB, Munoz A, Speizer FE (1987): Assessment of genetic and nongenetic influences on pulmonary function. Am Rev Respir Dis 135:217-222. 
18. Saunders NA, Leeder SR, Rebuck AS (1976): Ventilatory response to carbon dioxide in young athletes: a family study. Am Rev Respir Dis 113:497-502.

19. Shea SA, Walter J, Murphy K, Guz A (1987a): Evidence for individuality of breathing patterns in resting healthy man. Respir Physiol 68:331-344.

20. Shea SA, Walter J, Pelley C, Murphy K, Guz A (1987b): The effect of visual and auditory stimuli upon resting ventilation in man. Respir Physiol 68:345-357.

21. Shea SA, Murphy K, Hamilton R, Benchetrit G, Guz A (1988): Do the changes in respiratory pattern and ventilation seen with different behavioural situations reflect metabolic demands? In von Euler C, Katz-Salamon M (eds): Respiratory Psychophysiology, Wenner-Gren International Symposium Series, Vol. 50; Basingstoke: MacMillan Press, pp. 21-28.

22. Shea SA, Benchetrit G, Pham Dinh T, Hamilton RD, Guz A (1989): The breathing patterns of identical twins. Respir Physiol 75:211-224.

23. Shea SA, Guz A (1992): Personnalité ventilatoire - an overview. Respir Physiol 87:275-291.

24. Snedecor GW, Cochran WG (1980): Statistical Methods (7th ed). Iowa: Iowa State University Press.

Correspondence: S.A. Shea, Physiology Program, Harvard School of Public Health, 665 Huntington Avenue, Boston, MA 02115, USA. 